\title{
Life Table Analysis of Child Survival of Under-Five Age (0-59 Months) Children in Bangladesh
}

\author{
Md. Musa Khan ${ }^{1}$ \\ ${ }^{1} \mathrm{PhD}$ Fellow, Department of Statistics, Anadolu University, Eskisehir, Turkey
}

\begin{abstract}
This study uses data extracted from the Bangladesh Demographic and Health Survey (BDHS-2014) to investigate the predictors of child survival of under-five aged (0-59 months) in Bangladesh. The bivariate analysis and life table survival analysis techniques have been used to estimate the significant predictors of child survival in Bangladesh. Parents' education, occupation of father, region, type of toilet facility, access to mass media, type of place of residence, breastfeeding status, birth order, birth spacing with previous child, age of mother, age at first marriage and antenatal visit during pregnancy have been found significant effect on child survival by bivariate analysis and to estimate the probability of child survival by life table survival analysis technique. Finally, these findings suggest that an increase in parents' education, encourage mother to breastfeed to child, make conscious to mother to give birth at child bearing age 20-34 years, get married at legal age, ensure mother birth order little and improve health care services can raise child survival in Bangladesh.
\end{abstract}

Keywords: Child survival, Bivariate, Life table, BDHS, Antenatal.

\section{INTRODUCTION}

The study of child survival is becoming one of the most important research issues of the developing countries like Bangladesh. The total population of Bangladesh is 161.95million whereas the area is only 1, 47,570 square kilometers which represents that Bangladesh is one of the most densely populated countries in the world. Bangladesh population density is 1124.7 people per square kilometer as of December, 2016.The general mortality has a great improvement in Bangladesh but particularly level of infant and child mortality over the last four decades in Bangladesh remains noticeably high. Infant mortality dropped to about 38 per thousand live births in the 2014 Bangladesh Demographic and Health Survey (BDHS) from about 87 in the 1993 -1994 BDHS and child mortality dropped to about 8 per thousand live births in the 2014 BDHS from about 50 in the 1993-1994 BDHS (National Institute of Population Research and Training (NIPORT), 2009). Though such a reduction seems encouraging these national figures may mark large differentials in the risk of death that children of various sub groups of population. These sub groups are exposed to the decline in mortality may be attributed to the government's efforts to implement a national public health program, including the immunization of children. Successive five-year national development plans have been emphasizing reductions of infant and child mortality with varying targets. Some of the disparities are due to social and economic conditions (Bhuiyan, 1989). Thus, identification of the indicators which produce these differentials is very important to policy makers or governments in their efforts to improve child survival. Socio-economic factors that have typically been examined in relation to differential child survival in developing countries include education of mother, place of residence, father's occupation and household's economic condition (Caldwell, 1979). Recently, many of the demographic surveys in developing countries have been designed to collect information on this household's environmental condition. Mother's demographic factors that have typically been examined in relation to the differential of child survival in developing countries (Chowdhury, 1981). Birth interval, age of mother, birth order, and sex of child, which were the demographic characteristics, in relation to differential child survival (Ahmed, 1992). In a developing country like Bangladesh where the child mortality level is high as adjudicated by the standard of developing nation a study of factors influencing child mortality is of considerable relevance to planners and policy makers or developing countries' governments for the overall improvement of child survival and health. There is no room in doubt that both economic factors and modern information technology 
have had impacts on mortality decline in the developing countries during the recent years. Possibly, there are limits to the achievement of one in the absence of the other. It is believed that only after economic development of a nation crosses a certain doorstep and health programs can become fully effective to improve the mortality situation.

For Bangladesh, a nationwide study was conducted during the 1970s for better survival for urban children was also observed in. One such study was the Bangladesh Retrospective Survey of Fertility and Mortality (BRSFM), where a substantially higher child mortality rate was observed for rural than urban areas (Census Commission, 1977). On the basis of Bangladesh Fertility Survey (BFS) data, a similar tendency of higher child mortality among rural children was reported by many investigations (Al-Kabir, 1984). With this in view an attempt was made to investigate the effect of selected socioeconomic, demographic and environmental factors on child survival in Bangladesh. However, when the efforts of other variables like parental education, age of mother at birth facility were controlled, the pattern of urban-rural differentials was reversed (Trussell \& Slough, 1983). This indicated that the urban-rural differences might have been medicated through the other variables included in the analysis. The mother's working status exerts a significant negative influence; mother's education has a greater influence on child survival in Bangladesh than that of father's education (Majumder and Islam, 1993). The Bangladesh Bureau of Statistics (BBS) data show that infant mortality is higher for male children while child mortality is higher for female children. Several sources of data document indicate that child mortality decline was faster in the mid-1970s due to efforts given to the implementation of various progresses including availability of safe drinking water and immunization.

The literature review of child survival shows that a number of variables are affecting to child survival. However, the predictors of child survival are changing through time since the facilities, improvement of technology and awareness are changing day by day. Hence, it is essential to identify the portion of population where programs need strengthen in order to achieve the goal for increasing child survival.

In this study we examine the predictors of child survival under five-age children in Bangladesh and also determine the probability of child survival by life table analysis. Finally, we will recommend feasible strategies to increase child survival in Bangladesh.

\section{MAterials AND MethodS}

This study uses data extracted from the Bangladesh Demographic and Health Survey (BDHS2014), which was conducted during the period from May 21 to November 17, 2014 on behalf of the Government of Bangladesh by National Institute for Population Research and Training (NIPORT), with funding from the United States Agency for International Development (USAID)/Dhaka. The description of the survey can be found elsewhere. The sampling frame for the survey considered all households in Bangladesh from which a nationally representative sample of 17,989 households was selected; 17,565 were occupied. Of the households occupied, 17,300 (99\%) were successfully interviewed. In these households, a total of 18,245 ever-married females aged 15-49 years were identified as eligible for individual interview. Of them, 17863 females (or 98\%) were successfully interviewed. Among the 17863 ever-married females, the numbers of urban and rural respondents are $6167(34.52 \%)$ and 11696 (65.48\%), respectively. The sample had been taken 5 years prior to BDHS2014 survey. A total of 6150 children, under-five year age has been selected in the study of whom 361 (5.87\%) has already dead and $5789(94.13 \%)$ have still surviving at date of survey. The relationship between child survival and selected explanatory variables has been tested by applying bivariate analysis. Bivariate analysis has been carried out to assess the association of child survival under-five aged and selected characteristics using chi-square $(\chi 2)$ statistic. Life Table Analysis is the second step of determining the probability of child survival in Bangladesh. To create life table standardized data are used.

\subsection{Life Table Analysis}

In child survival analysis, we know that the children who have been survived a certain number of months already, but we do not know how much longer they will be survived. It is, therefore, necessary to use estimation methods appropriate for censored data. The contents of the columns of the actuarial life table are based on the method of Kaplan and Meier (1958). Kaplan and Meier developed the product limit (PL) method for estimating survivorship function. Since the data of the child survival have already been grouped into intervals and the sample size is very large, so it may be more convenient to perform a life table analysis. A statistical technique useful for this type of data is called 
a follow up life table. The basic idea of the life table is to subdivide the period of observation into smaller time intervals. For each interval, children who have been observed at the time of interview are used to calculate the probability of a terminal event occurring in that interval. The probabilities estimated from each of the intervals are then used to estimate the overall probability of the event at occurring at different time points. The analysis of child survival data from the last closed interval shows and apparent observation bias due to recall problems which results in heaping phenomena at every completed 6 months the extent of heaping can be considered as an indication of the quality of data. Data for the current open interval avoid particular trap. Moreover, the distributions include the duration of surviving regardless of whether the child has died or not. In order to minimize these mentioned biases, a current status analysis of open interval is performed by life table approach.

\subsection{Creating Life Table}

The life table is computed for this analysis by the SPSS program where the duration of child surviving is the survival time variable and usual interval is used. The contents of the columns of the life table are as follows:

Interval start time: It is beginning value for each interval. Each interval extends from its starts time up to the start time of the next interval.

Number entering this interval: The number of cases that have survived to the beginning of the current interval. That is survived to the beginning of interval between $x$ to $(x+i)$ is $n x, i=1,2, \ldots, n$

Number withdrawn during this interval: The number of cases that entered at the time $\mathrm{x}$ and whose follow-up ends at time $(x+i)$ is $C x$. These are censored cases. That is, these are cases for which the event of interest has not occurred at the last contact.

Number exposed to risk ( $\mathrm{Nx})$ : This is calculated as the number of cased entering between interval $\mathrm{x}$ to $(\mathrm{x}+\mathrm{i})$ minus one-half of those withdrawn during the interval, i.e. $\mathrm{Nx}=\mathrm{nx}-\frac{C_{x}}{2}$.

Number of terminal events (Dx): The number of observations for whom the event of interest occurs between the interval $x$ to $(x+i)$ is Dx.

Proportion of terminal events (qx): An estimate of the probability of the event of interest occurring in an interval for a case that has made it to the beginning of that interval. It is exposed to risk $\mathrm{qx}=\frac{D_{x}}{N_{x}}$ Proportion surviving $(\mathrm{Px})$ : The proportion surviving is one minus the proportion of terminal events i.e. $P x=1-q x$

Cumulative proportion surviving at end: This is an estimate of the probability surviving to the end of an interval. It is computed as the product of the proportion surviving this interval and the proportion surviving all previous intervals. This is also called cumulative survival fruition or simply survival function.

\subsection{Variables}

In this study, we consider the important variables which are education of mother; age of mother; education of father; economic status; occupation of father; type of place of residence; region; type of toilet facility; sources of drinking water; access to mass media; breastfeeding status; birth order; birth spacing with previous child; age at first marriage; place of delivery and antenatal visit during pregnancy.

\section{RESULTS AND DiSCUSSION}

In this section, we examine the predictors and significant determinants of child survival in Bangladesh. Child survival status of a nation represents a country's level of socio-economic development and quality of life. During the last four decades Bangladesh, has witnessed a large decline in child mortality this means that child survival rate is raising. The child survival in Bangladesh varies according to socio-economic, bio-demographic and health care characteristics of the population concerned. There are many predictors of child survival in a particular group of 
variables and it is necessary to analyze them separately in order to get the idea about the insight variation of that particular type of variables.

The percentage distribution of child survival by socio-economic, bio-demographic and health care variables is shown in Table-1. The result shows that among selected variables education of mother, education of father, region, breastfeeding status, birth order, birth spacing with previous child, antenatal visit during pregnancy are the most significant at $1 \%$ level of significance. This means that these factors have significant effect on child survival in Bangladesh. Economic status, type of place of residence, type of toilet facility, access to mass media, age of mother, age at first marriage are significant at 5\% level of significance whereas occupation of father is significant at $10 \%$ level of significance. But selected variables sources of drinking water, sex of child and place of delivery variables are not statistically significant.

Table-2 represents the probability distribution of child survival in Bangladesh obtained from survival analysis of selected statistically significant variables. The mothers having no schooling (0.9207), their children probability of survivals less than children of mothers with primary (0.9325) or higher education (0.9505). Various factors may cause decline the child survival with mothers' education. First, these educated mothers know how to take care their children properly. Secondly, these educated mothers conscious their children how to save their life. In the same way, primary or higher educated father's children more survive than the no schooling of father. There is variation in child survival among six administrative divisions. It is seen that the child survival of Barisal division starts at 0.9501 level and end 59 months 0.9297 level, Chittagong division starts 0.9401 level and reaches to 0.9163 at the end of 59 months, Dhaka division children starts at 0.9226 , reaches to 0.9071 at end of 59 months, Khulna division starts at 0.9487 and end 59 months at 0.9445 level, Rajshahi division children survival starts at 0.9344 level and ends at 0.9221 level, the child survival of Sylhet division starts at 0.9077 level and reaches to 0.8959 at the end of 59 months. That is the child survival probability is the lowest (0.9077) in Sylhet division and the highest in Barisal division (0.9501). Age of mother at birth of index child exhibits a positive association with survival. The children of women aged less than 20 years survive 0.9155 at the beginning and reaching to 0.8977 at the end of 59 months, children of women aged 20-34 years survive 0.9397 at the beginning and reaching to 0.9251 at the end of 59 months and the children of women aged 35+ beginning at 0.99078 and reaching to 0.8913 at the last point of 59 months. Therefore, probability of child survival is highest of women aged 20-34 years. Birth spacing of previous child is positively associated with child survival. If birth interval increases then child survival increases and birth interval is short then child survival decreases. It is clear that children of birth spacing of previous child 36 months and above survival probability (0.9432) is more than that of children of birth spacing of child less than 24 than months (0.9154) or 24-35 months (0.9320). Birth order demonstrates a positive association with child survival. Children of women with parity 2-3 have higher survival probability (0.9464) than women with parity 1 $(0.9203)$ or $4+(0.9254)$. It represents that children of women with parity 2-3 survival starts at 0.9464 level, reaches to 0.9316 at the end of 59 months. The decrease in child survival rate in Bangladesh with birth order may reflect a more powerful competition faced by higher birth order children in terms of caregivers' time, medical resources and nutritious food while children needed. Economic status of father is associated with child survival. At the starting children of higher classes survive 0.9426 levels and at the end survive at 0.9392 up to 48 months where children of poor classes survive 0.9155 at the beginning and reaching to 0.8950 at the end of 48 months. It is seen that children of poor economic status of father survive less $(0.9155)$ than children come from middle class $(0.9365)$

Table1: Percentage distribution of child survival in Bangladesh according to selected variables

\begin{tabular}{|c|c|c|c|c|c|}
\hline \multirow[t]{2}{*}{ Selected Variables } & \multicolumn{2}{|c|}{ No of Children } & \multirow[t]{2}{*}{ Total } & \multirow{2}{*}{$\begin{array}{l}\text { Percentage of } \\
\text { Alive }\end{array}$} & \multirow{2}{*}{$\begin{array}{c}\text { Chi-square } \\
\left(\chi^{2}\right)\end{array}$} \\
\hline & Alive & Dead & & & \\
\hline \multicolumn{6}{|c|}{ Education of Mother } \\
\hline Illiterate & $1706(29.6 \%)$ & $131(36.3 \%)$ & $1837(29.9 \%)$ & $92.9 \%$ & \multirow{3}{*}{$12.830 * * *$} \\
\hline Primary & $1660(28.8 \%)$ & $113(31.3 \%)$ & $1773(28.8 \%)$ & $93.6 \%$ & \\
\hline Secondary+ & $2423(41.8 \%)$ & $117(32.4 \%$ & $2540(41.3 \%)$ & $95.4 \%$ & \\
\hline \multicolumn{6}{|c|}{ Education of Father } \\
\hline Illiterate & $2066(35.6 \%)$ & $165(45.7 \%)$ & $2231(36.3 \%)$ & $92.6 \%$ & \\
\hline
\end{tabular}


Life Table Analysis of Child Survival of Under-Five Age (0-59 Months) Children in Bangladesh

\begin{tabular}{|c|c|c|c|c|c|}
\hline Primary & $1506(26.0 \%)$ & $109(30.2 \%)$ & $1615(26.3 \%)$ & $93.3 \%$ & \multirow[t]{2}{*}{$26.356^{* * *}$} \\
\hline Secondary+ & $2217(38.4 \%)$ & $87(24.1 \%)$ & $2304(37.5 \%)$ & $96.2 \%$ & \\
\hline \multicolumn{6}{|c|}{ Economic Status } \\
\hline Poor & $2340(40.5 \%)$ & $164(45.4 \%)$ & $2504(40.7 \%)$ & $93.4 \%$ & \multirow{3}{*}{$6.549 * *$} \\
\hline Middle & $1079(18.6 \%)$ & $74(20.5 \%)$ & $1153(18.7 \%)$ & $93.6 \%$ & \\
\hline Rich & $2370(40.9 \%)$ & $123(34.1 \%$ & $2493(40.6 \%)$ & $95.1 \%$ & \\
\hline \multicolumn{6}{|c|}{ Occupation of Father } \\
\hline Agriculture & $1288(22.2 \%)$ & $93(25.8 \%)$ & $1381(22.5 \%)$ & $93.3 \%$ & \multirow{4}{*}{$6.729 *$} \\
\hline Business & $1335(23.1 \%)$ & $68(18.8 \%)$ & $1403(22.8 \%)$ & $95.2 \%$ & \\
\hline Service & $678(11.7 \%)$ & $34(9.4 \%)$ & $712(11.6 \%)$ & $95.2 \%$ & \\
\hline Others & $2488(43.0 \%)$ & $166(46.0 \%)$ & $2654(43.2 \%)$ & $93.7 \%$ & \\
\hline \multicolumn{6}{|c|}{ Type of Place of Residence } \\
\hline Urban & $2007(34.7 \%)$ & $100(27.7 \%)$ & $2107(34.3 \%)$ & $95.2 \%$ & \multirow{2}{*}{$5.587 * *$} \\
\hline Rural & $3782(65.3 \%)$ & $261(72.3 \%)$ & $4043(65.7 \%)$ & $93.5 \%$ & \\
\hline \multicolumn{6}{|c|}{ Region } \\
\hline Barisal & $748(13.0 \%)$ & $41(11.6 \%)$ & $791(12.9 \%)$ & $94.6 \%$ & \multirow{6}{*}{$28.089 * * *$} \\
\hline Chittagong & $1201(20.7 \%)$ & $74(20.5 \%)$ & $1275(20.7 \%)$ & $94.2 \%$ & \\
\hline Dhaka & $1224(21.1 \%)$ & $61(16.9 \%)$ & $1285(20.9 \%)$ & $95.2 \%$ & \\
\hline Khulna & $681(11.8 \%)$ & $33(9.2 \%)$ & $714(11.6 \%)$ & $95.4 \%$ & \\
\hline Rajshahi & $917(15.8 \%)$ & $50(13.9 \%)$ & $967(15.7 \%)$ & $94.8 \%$ & \\
\hline Sylhet & $1018(17.6 \%)$ & $100(27.8 \%)$ & $1118(18.2 \%)$ & $91.1 \%$ & \\
\hline \multicolumn{6}{|c|}{ Type of Toilet Facility } \\
\hline Open Latrine & $3455(59.7 \%)$ & $225(62.3 \%)$ & $3680(59.8 \%)$ & $93.9 \%$ & \multirow{3}{*}{$6.245^{* *}$} \\
\hline Sanitary Latrine & $1433(24.8 \%)$ & $65(18.0 \%)$ & $1498(24.4 \%)$ & $95.7 \%$ & \\
\hline Others & $901(15.5 \%)$ & $71(19.7 \%)$ & $972(15.8 \%)$ & $92.7 \%$ & \\
\hline \multicolumn{6}{|c|}{ Sources of Drinking Water } \\
\hline Pond/River/Others & $5000(86.5 \%)$ & $313(86.7 \%)$ & $5313(86.4 \%)$ & $94.1 \%$ & \multirow[b]{2}{*}{0.375} \\
\hline Tube-Well/Pipe & $789(13.5 \%)$ & $49(13.3 \%)$ & $837(13.6 \%)$ & $94.3 \%$ & \\
\hline \multicolumn{6}{|c|}{ Access to Mass Media } \\
\hline No Access & $2195(38.0 \%)$ & $160(44.3 \%)$ & $2355(38.3 \%)$ & $93.2 \%$ & \multirow[b]{2}{*}{$3.550 * *$} \\
\hline Having Access & $3594(62.0 \%)$ & $201(55.7 \%)$ & $3795(61.7 \%)$ & $94.7 \%$ & \\
\hline \multicolumn{6}{|c|}{ Breastfeeding Status } \\
\hline $\begin{array}{l}\text { Never Breast } \\
\text { feeding }\end{array}$ & $47(0.8)$ & $132(36.6 \%)$ & $179(2.9 \%)$ & $26.3 \%$ & \multirow{4}{*}{$1772.610 * * *$} \\
\hline$\leq 11$ months & $1367(23.6 \%)$ & $196(54.3 \%)$ & $1563(25.4 \%)$ & $87.4 \%$ & \\
\hline 12-23 months & $1690(29.2 \%)$ & $27(7.5 \%)$ & $1717(27.9 \%)$ & $98.4 \%$ & \\
\hline$\geq 24$ months & $2685(46.4 \%)$ & $6(1.6 \%)$ & $2691(43.8 \%)$ & $99.8 \%$ & \\
\hline & & Birth C & der & & \\
\hline 1 & $1904(32.9 \%)$ & $135(37.4 \%)$ & $2039(33.2 \%)$ & $93.4 \%$ & \\
\hline $2-3$ & $2499(43.1 \%)$ & $124(34.3 \%)$ & $2623(42.7 \%)$ & $95.3 \%$ & $11.645 * * *$ \\
\hline $4+$ & $1386(24.0 \%)$ & $102(28.3 \%)$ & $1488(24.2 \%)$ & $93.1 \%$ & \\
\hline & & irth Spacing witl & Previous Child & & \\
\hline$\leq 23$ months & $1685(29.1 \%)$ & $155(42.9 \%)$ & $1840(29.9 \%)$ & $91.6 \%$ & \\
\hline 24-35 months & $1258(21.7 \%)$ & $70(19.4 \%)$ & $1328(21.6 \%)$ & $94.7 \%$ & $29.432 * * *$ \\
\hline$\geq 36$ months & $2846(49.2 \%)$ & $136(37.7 \%)$ & $2982(48.5 \%)$ & $95.4 \%$ & \\
\hline & & Age of 1 & ther & & \\
\hline$<20$ years & $818(14.1 \%)$ & $67(18.6 \%)$ & $885(14.4 \%)$ & $92.4 \%$ & \\
\hline 20-34yers & $4356(75.2 \%)$ & $4621(75.1 \%)$ & $4621(75.1 \%)$ & $94.3 \%$ & $6.963 * *$ \\
\hline$>34$ years & $615(10.6 \%)$ & $29(8.0 \%)$ & $644(10.5 \%)$ & $95.5 \%$ & \\
\hline & & Age at First & Marriage & & \\
\hline$\leq 14$ years & $2296(39.7 \%)$ & $160(44.3 \%)$ & $2456(40.0 \%)$ & $93.5 \%$ & \\
\hline $15-17$ years & $2246(38.8 \%)$ & $141(39.1 \%)$ & $2387(38.8 \%)$ & $94.1 \%$ & $6.422 * *$ \\
\hline$\geq 18$ years & $1247(21.5 \%)$ & $60(16.6 \%)$ & $1307(21.2 \%)$ & $95.4 \%$ & \\
\hline & & Sex of & hild & & \\
\hline Male & $2930(50.6 \%)$ & $189(52.4 \%)$ & $3119(50.7 \%)$ & $93.9 \%$ & \\
\hline Female & $2859(49.4 \%)$ & $172(47.6 \%)$ & $3031(49.3 \%)$ & $94.3 \%$ & 0.410 \\
\hline & & Place of 1 & livery & & \\
\hline Home & $4783(82.7 \%)$ & $307(85.0 \%)$ & $5090(82.8 \%)$ & $93.9 \%$ & \\
\hline Hospital/Others & $1006(17.3 \%)$ & $54(15.0 \%)$ & $1060(17.2 \%)$ & $94.9 \%$ & 1.379 \\
\hline
\end{tabular}




\begin{tabular}{|c|l|l|l|l|l|}
\hline \hline \multicolumn{5}{|c|}{ Antenatal Visit During Pregnancy } \\
\cline { 1 - 4 } No & $2810(48.5 \%)$ & $282(78.2 \%)$ & $3092(50.3 \%)$ & $90.9 \%$ & \multirow{2}{*}{$117.484 * * *$} \\
\hline At least one time & $2979(51.5 \%)$ & $79(21.8 \%)$ & $3058(49.7 \%)$ & $97.4 \%$ & \\
\hline Total(n) & 5789 & 361 & 6150 & & \\
\hline \multicolumn{7}{|c|}{$* * *$ Significant at 1\%, ** Significant at 5\% and * Significant at 10\% } \\
\hline
\end{tabular}

Table2: Probability distribution of child survival in Bangladesh obtained from survival analysis of selected statistically significant variables.

\begin{tabular}{|c|c|c|c|c|c|c|}
\hline \multirow[t]{2}{*}{ Variable } & \multirow[t]{2}{*}{ Category } & \multicolumn{5}{|c|}{ Probability of survival of child up to months } \\
\hline & & 0 & $\leq 12$ & $\leq 24$ & $\leq 36$ & $\leq 48$ \\
\hline \multirow{3}{*}{$\begin{array}{l}\text { Education } \\
\text { of mother }\end{array}$} & Illiterate & 0.9207 & 0.9078 & 0.9006 & 0.8973 & 0.8973 \\
\hline & primary & 0.9325 & 0.9275 & 0.9257 & 0.9242 & 0.9242 \\
\hline & Secondary & 0.9505 & 0.9428 & 0.9417 & 0.9397 & 0.9397 \\
\hline \multirow{3}{*}{$\begin{array}{l}\text { Education } \\
\text { of father }\end{array}$} & Illiterate & 0.9223 & 0.9110 & 0.9068 & 0.9022 & 0.9022 \\
\hline & Primary & 0.9384 & 0.9273 & 0.9222 & 0.9222 & 0.9222 \\
\hline & Secondary + & 0.9406 & 0.9362 & 0.9335 & 0.9320 & 0.9320 \\
\hline \multirow[t]{6}{*}{ Region } & Barisal & 0.9501 & 0.9390 & 0.9339 & 0.9297 & 0.9297 \\
\hline & Chittagong & 0.9401 & 0.9239 & 0.9186 & 0.9163 & 0.9163 \\
\hline & Dhaka & 0.9226 & 0.9153 & 0.9091 & 0.9671 & 0.9071 \\
\hline & Khulna & 0.9487 & 0.9487 & 0.9487 & 0.9445 & 0.9445 \\
\hline & Rajshahi & 0.9344 & 0.9260 & 0.9245 & 0.9221 & 0.9221 \\
\hline & Sylhet & 0.9077 & 0.9002 & 0.8959 & 0.8959 & 0.8959 \\
\hline \multirow{3}{*}{$\begin{array}{l}\text { Age of } \\
\text { mother }\end{array}$} & $<20$ years & 0.9155 & 0.9010 & 0.8977 & 0.8977 & 0.8977 \\
\hline & 20-34 years & 0.9397 & 0.9315 & 0.9275 & 0.9251 & 0.9251 \\
\hline & $35+$ years & 0.9078 & 0.8991 & 0.8947 & 0.8913 & 0.8913 \\
\hline \multirow{3}{*}{$\begin{array}{l}\text { Birth } \\
\text { spacing } \\
\text { with } \\
\text { previous } \\
\text { child }\end{array}$} & $<24$ months & 0.9154 & 0.8994 & 0.8951 & 0.8951 & 0.8951 \\
\hline & 24-35months & 0.9320 & 0.9240 & 0.9174 & 0.138 & 0.9130 \\
\hline & 36+months & 0.9432 & 0.9377 & 0.9353 & 0.9323 & 0.9323 \\
\hline \multirow[t]{3}{*}{ Birth order } & 1 & 0.9203 & 0.9112 & 0.9101 & 0.9101 & 0.9101 \\
\hline & $2-3$ & 0.9464 & 0.9407 & 0.9360 & 0.9816 & 0.9316 \\
\hline & $4+$ & 0.9254 & 0.9119 & 0.9060 & 0.9044 & 0.9044 \\
\hline \multirow{4}{*}{$\begin{array}{l}\text { Occupation } \\
\text { of father }\end{array}$} & Service & 0.9396 & 0.9346 & 0.9318 & 0.9318 & 0.9318 \\
\hline & Business & 0.9401 & 0.9272 & 0.9247 & 0.9207 & 0.9207 \\
\hline & Agriculture & 0.9346 & 0.9252 & 0.9198 & 0.9180 & 0.9180 \\
\hline & Other & 0.9209 & 0.9129 & 0.9082 & 0.9050 & 0.9050 \\
\hline \multirow{2}{*}{$\begin{array}{l}\text { Type of } \\
\text { place of } \\
\text { residence }\end{array}$} & Rural & 0.9234 & 0.9065 & 0.9020 & 0.9010 & 0.9011 \\
\hline & Urban & 0.9399 & 0.9319 & 0.9281 & 0.9266 & 0.9259 \\
\hline \multirow{3}{*}{$\begin{array}{l}\text { Economic } \\
\text { status }\end{array}$} & Poor & 0.9155 & 0.9036 & 0.8989 & 0.8950 & 0.8950 \\
\hline & Middle & 0.9365 & 0.9263 & 0.9217 & 0.9192 & 0.9192 \\
\hline & Higher & 0.9426 & 0.9406 & 0.9392 & 0.9392 & 0.9392 \\
\hline \multirow{3}{*}{$\begin{array}{l}\text { Type of } \\
\text { toilet } \\
\text { facility }\end{array}$} & Sanitary & 0.9540 & 0.9501 & 0.9501 & 0.9501 & 0.9501 \\
\hline & Open Latrine & 0.9285 & 0.9146 & 0.9106 & 0.9071 & 0.9071 \\
\hline & Others & 0.9311 & 0.9235 & 0.9189 & 0.9167 & 0.9167 \\
\hline \multirow{3}{*}{$\begin{array}{l}\text { Age at first } \\
\text { marriage }\end{array}$} & $\leq 14$ years & 0.9145 & 0.9016 & 0.8979 & 0.8952 & 0.8951 \\
\hline & 15-17years & 0.9366 & 0.9268 & 0.9227 & 0.9182 & 0.9192 \\
\hline & $\geq 18$ years & 0.9446 & 0.9426 & 0.9399 & 0.9399 & 0.9396 \\
\hline \multirow{2}{*}{$\begin{array}{l}\text { Access to } \\
\text { mass } \\
\text { media }\end{array}$} & No & 0.9224 & 0.9095 & 0.953 & 0.9011 & 0.9011 \\
\hline & Yes & 0.9379 & 0.9309 & 0.9271 & 0.9256 & 0.9255 \\
\hline \multirow{4}{*}{$\begin{array}{l}\text { Breast- } \\
\text { feeding } \\
\text { status }\end{array}$} & $\begin{array}{l}\text { Never breast } \\
\text { feeding }\end{array}$ & 0.9206 & 0.9077 & 0.9005 & 0.8973 & 0.8973 \\
\hline & $\leq 11$ months & 0.9325 & 0.9275 & 0.9267 & 0.9243 & 0.9242 \\
\hline & $12-23$ months & 0.9505 & 0.9418 & 0.9417 & 0.9397 & 0.9399 \\
\hline & $\geq 24$ months & 0.9541 & 0.9500 & 0.9502 & 0.9501 & 0.9504 \\
\hline \multirow{2}{*}{$\begin{array}{l}\text { Antenatal } \\
\text { visit during } \\
\text { pregnancy }\end{array}$} & No & 0.9124 & 0.9095 & 0.963 & 0.9021 & 0.9031 \\
\hline & At least one time & 0.9479 & 0.9409 & 0.9371 & 0.9256 & 0.9355 \\
\hline
\end{tabular}


or higher class $(0.9426)$. There is no marked variation in child survival among four categories of father's occupation. Children whose father is service holder survives 0.9396 at the starting and at the end 0.9318 survive. A child whose father is businessman survives 0.9401 at the starting and 0.9207 survives up to 48 months. For agriculture, 0.9346survives at the beginning and 0.9180 survive up to 48 months and for other category which is 0.9209 at the starting, reaching 0.9050 at the end of 48 months. It is realized that children belonging with sanitary facility their survival probability starting (0.9540) to ending (0.9501) is more than open latrine (0.9285) or others toilet facility 0.9311). Age at first marriage at $\leq 14$ years their children starting survival probability is 0.9145 and ending survival probability is 0.8951 at the end of 59 months whereas age at first marriage at 15-17 years their children survival probability starts at 0.9366 and reach to 0.9192 at the end of 59 months. But age at first marriage $\geq 18$ year's mother's children starting survival probability is 0.9446 and ending probability is 0.9396 . Access to mass media is positively associated with child survival. It reflects that children of access to mass media survival start at 0.9379 , reaching to 0.9255 at the end of 48 months while children do not access to mass media survival start at 0.9224 and survive 0.9011 up to 48 months. Therefore, children of access to mass media survival probability are higher than the children do not access to mass media. Type of place of residence has a significant on child survival. It is observed that rural child survival probability is less than urban child survival probability for all age level of child. Never breastfeeding children survival probability starts at 0.9206 and ends at 0.8739 . Breastfeeding $\leq 11$ month's children beginning survival probability is (0.9325) and ending survival probability is $(0.9242)$ whereas breastfeeding $12-23$ months' children survival probability starts at 0.9505 and reaches to 0.9399 at the end of 59 months. But breastfeeding of $\geq 24$ month's children starting survival probability is 0.9541 and ending probability is 0.9505 . It is clear that child survival is less of never breastfeeding of children compare to breastfeeding of children of different levels. Antenatal visit during pregnancy has a positive relation to child survival. It shows that no visit to doctor during pregnancy of mother's children survival probability starts at 0.9124 and reaches to 0.9031 while at least one time visit to doctor during pregnancy starting survival probability is 0.9479 and ending probability is 0.9355 . Therefore, child survival of at least one time visit to doctor during pregnancy of mother's children is higher than no visit during pregnancy of mother. The maternal health care services variables have strong indirect influence in increasing child survival, because the mothers who sought antenatal care during pregnancy are well aware about utilization of existing health facilities and they can properly utilize such facilities when needed for their child.

Table3: Survival function of under-five aged (0-59 months) children for Bangladesh by Life Table Analysis

\begin{tabular}{|l|l|l|l|l|l|l|l|}
\hline $\begin{array}{l}\text { Interval } \\
\text { start } \\
\text { time } \\
\text { (Months) }\end{array}$ & $\begin{array}{l}\text { Number } \\
\text { entering } \\
\text { this } \\
\text { interval } \\
\left(\mathrm{n}_{\mathrm{x})}\right.\end{array}$ & $\begin{array}{l}\text { Number } \\
\text { withdrawn } \\
\text { during } \\
\text { interval }\left(\mathrm{C}_{\mathrm{x})}\right.\end{array}$ & $\begin{array}{l}\text { Number } \\
\text { exposed } \\
\text { to risk } \\
\left(\mathrm{N}_{\mathrm{x})}\right.\end{array}$ & $\begin{array}{l}\text { Number of } \\
\text { terminal } \\
\text { events } \\
\left(\mathrm{D}_{\mathrm{x})}\right.\end{array}$ & $\begin{array}{l}\text { Proportion } \\
\text { terminating } \\
\left(\mathrm{q}_{\mathrm{x}}\right.\end{array}$ & $\begin{array}{l}\text { Proportion } \\
\text { surviving } \\
\left(\mathrm{P}_{\mathrm{x})}\right.\end{array}$ & $\begin{array}{l}\text { Cumulative } \\
\text { proportion } \\
\text { surviving } \\
\left(\mathrm{l}_{\mathrm{x})}\right.\end{array}$ \\
\hline 0.0 & 6908.0 & 67.0 & 6874.5 & 274.0 & 0.0399 & 0.9601 & 0.9601 \\
\hline 1.0 & 6567.0 & 95.0 & 6519.5 & 37.0 & 0.0057 & 0.9943 & 0.9547 \\
\hline 2.0 & 6435.0 & 137.0 & 6366.5 & 18.0 & 0.0028 & 0.9972 & 0.9520 \\
\hline 3.0 & 6280.0 & 132.0 & 6214.0 & 14.0 & 0.0023 & 0.9977 & 0.9498 \\
\hline 4.0 & 6134.0 & 116.0 & 6076.0 & 11.0 & 0.0018 & 0.9982 & 0.9481 \\
\hline 5.0 & 6007.0 & 137.0 & 5938.5 & 18.0 & 0.0030 & 0.9970 & 0.9453 \\
\hline 6.0 & 5852.0 & 117.0 & 5793.5 & 16.0 & 0.0028 & 0.9972 & 0.9426 \\
\hline 7.0 & 5719.0 & 110.0 & 5664.0 & 10.0 & 0.0018 & 0.9982 & 0.9410 \\
\hline 8.0 & 5599.0 & 98.0 & 5550.0 & 8.0 & 0.0014 & 0.9986 & 0.9396 \\
\hline 9.0 & 5493.0 & 78.0 & 5454.0 & 6.0 & 0.0011 & 0.9989 & 0.9386 \\
\hline 10.0 & 5409.0 & 85.0 & 5366.5 & 3.0 & 0.0006 & 0.9994 & 0.9381 \\
\hline 11.0 & 5321.0 & 106.0 & 5268.0 & 6.0 & 0.0011 & 0.9989 & 0.9370 \\
\hline 12.0 & 5209.0 & 111.0 & 5153.5 & 11.0 & 0.0021 & 0.9979 & 0.9350 \\
\hline 13.0 & 5087.0 & 123.0 & 5025.5 & 6.0 & 0.0012 & 0.9988 & 0.9339 \\
\hline 14.0 & 4958.0 & 121.0 & 4897.5 & .0 & 0.0000 & 1.0000 & 0.9339 \\
\hline 15.0 & 4837.0 & 124.0 & 4775.0 & 4.0 & 0.0008 & 0.9992 & 0.9331 \\
\hline 16.0 & 4709.0 & 115.0 & 4651.5 & 5.0 & 0.0011 & 0.9989 & 0.9321 \\
\hline 17.0 & 4589.0 & 128.0 & 4525.0 & 2.0 & 0.0004 & 0.9996 & 0.9317 \\
\hline 18.0 & 4459.0 & 115.0 & 4401.5 & 3.0 & 0.0007 & 0.9993 & 0.9310 \\
\hline 19.0 & 4341.0 & 79.0 & 4301.5 & 5.0 & 0.0012 & 0.9988 & 0.9300 \\
\hline 20.0 & 4257.0 & 79.0 & 4217.5 & 3.0 & 0.0007 & 0.9993 & 0.9293 \\
\hline
\end{tabular}


Md. Musa Khan

\begin{tabular}{|c|c|c|c|c|c|c|c|}
\hline 21.0 & 4175.0 & 75.0 & 4137.5 & 1.0 & 0.0002 & 0.9998 & 0.9291 \\
\hline 22.0 & 4099.0 & 75.0 & 4061.5 & 1.0 & 0.0002 & 0.9998 & 0.9289 \\
\hline 23.0 & 4023.0 & 102.0 & 3972.0 & 3.0 & 0.0008 & 0.9992 & 0.9282 \\
\hline 24.0 & 3918.0 & 119.0 & 3858.5 & 11.0 & 0.0029 & 0.9971 & 0.9255 \\
\hline 25.0 & 3788.0 & 134.0 & 3721.0 & 0.0 & 0.0000 & 1.0000 & 0.9255 \\
\hline 26.0 & 3654.0 & 134.0 & 3587.0 & 1.0 & 0.0003 & 0.9997 & 0.9252 \\
\hline 27.0 & 3519.0 & 139.0 & 3449.5 & 0.0 & 0.0000 & 1.0000 & 0.9252 \\
\hline 28.0 & 3380.0 & 142.0 & 3309.0 & 0.0 & 0.0000 & 1.0000 & 0.9252 \\
\hline 29.0 & 3238.0 & 113.0 & 3181.5 & 0.0 & 0.0000 & 1.0000 & 0.9252 \\
\hline 30.0 & 3125.0 & 99.0 & 3075.5 & 2.0 & 0.0007 & 0.9993 & 0.9246 \\
\hline 31.0 & 3024.0 & 96.0 & 2976.0 & 0.0 & 0.0000 & 1.0000 & 0.9246 \\
\hline 32.0 & 2928.0 & 93.0 & 2881.5 & 0.0 & 0.0000 & 1.0000 & 0.9246 \\
\hline 33.0 & 2835.0 & 91.0 & 2789.5 & 0.0 & 0.0000 & 1.0000 & 0.9246 \\
\hline 34.0 & 2744.0 & 93.0 & 2697.5 & 0.0 & 0.0000 & 1.0000 & 0.9246 \\
\hline 35.0 & 2651.0 & 71.0 & 2615.5 & 0.0 & 0.0000 & 1.0000 & 0.9246 \\
\hline 36.0 & 2580.0 & 130.0 & 2515.0 & 5.0 & 0.0020 & 0.9980 & 0.9228 \\
\hline 37.0 & 2445.0 & 106.0 & 2392.0 & 0.0 & 0.0000 & 1.0000 & 0.9228 \\
\hline 38.0 & 2339.0 & 139.0 & 2269.5 & 0.0 & 0.0000 & 1.0000 & 0.9228 \\
\hline 39.0 & 2200.0 & 127.0 & 2136.5 & 0.0 & 0.0000 & 1.0000 & 0.9228 \\
\hline 40.0 & 2073.0 & 138.0 & 2004.0 & 0.0 & 0.0000 & 1.0000 & 0.9228 \\
\hline 41.0 & 1935.0 & 106.0 & 1882.0 & 0.0 & 0.0000 & 1.0000 & 0.9228 \\
\hline 42.0 & 1829.0 & 119.0 & 1769.5 & 0.0 & 0.0000 & 1.0000 & 0.9228 \\
\hline 43.0 & 1710.0 & 114.0 & 1653.0 & 0.0 & 0.0000 & 1.0000 & 0.9228 \\
\hline 44.0 & 1596.0 & 79.0 & 1556.5 & 0.0 & 0.0000 & 1.0000 & 0.9228 \\
\hline 45.0 & 1517.0 & 85.0 & 1474.5 & 0.0 & 0.0000 & 1.0000 & 0.9228 \\
\hline 46.0 & 1432.0 & 90.0 & 1387.0 & 0.0 & 0.0000 & 1.0000 & 0.9228 \\
\hline 47.0 & 1342.0 & 88.0 & 1298.0 & 0.0 & 0.0000 & 1.0000 & 0.9228 \\
\hline 48.0 & 1254.0 & 126.0 & 1191.0 & 0.0 & 0.0000 & 1.0000 & 0.9228 \\
\hline 49.0 & 1128.0 & 118.0 & 1069.0 & 0.0 & 0.0000 & 1.0000 & 0.9228 \\
\hline 50.0 & 1010.0 & 111.0 & 954.5 & 0.0 & 0.0000 & 1.0000 & 0.9228 \\
\hline 51.0 & 899.0 & 117.0 & 840.5 & 0.0 & 0.0000 & 1.0000 & 0.9228 \\
\hline 52.0 & 782.0 & 119.0 & 722.5 & 0.0 & 0.0000 & 1.0000 & 0.9228 \\
\hline 53.0 & 663.0 & 125.0 & 600.5 & 0.0 & 0.0000 & 1.0000 & 0.9228 \\
\hline 54.0 & 538.0 & 98.0 & 489.0 & 0.0 & 0.0000 & 1.0000 & 0.9228 \\
\hline 55.0 & 440.0 & 85.0 & 397.5 & 0.0 & 0.0000 & 1.0000 & 0.9228 \\
\hline 56.0 & 355.0 & 94.0 & 308.0 & 0.0 & 0.0000 & 1.0000 & 0.9228 \\
\hline 57.0 & 261.0 & 94.0 & 214.0 & 0.0 & 0.0000 & 1.0000 & 0.9228 \\
\hline 58.0 & 167.0 & 73.0 & 130.5 & 0.0 & 0.0000 & 1.0000 & 0.9228 \\
\hline 59.0 & 94.0 & 94.0 & 47.0 & 0.0 & 0.0000 & 1.0000 & 0.9228 \\
\hline
\end{tabular}

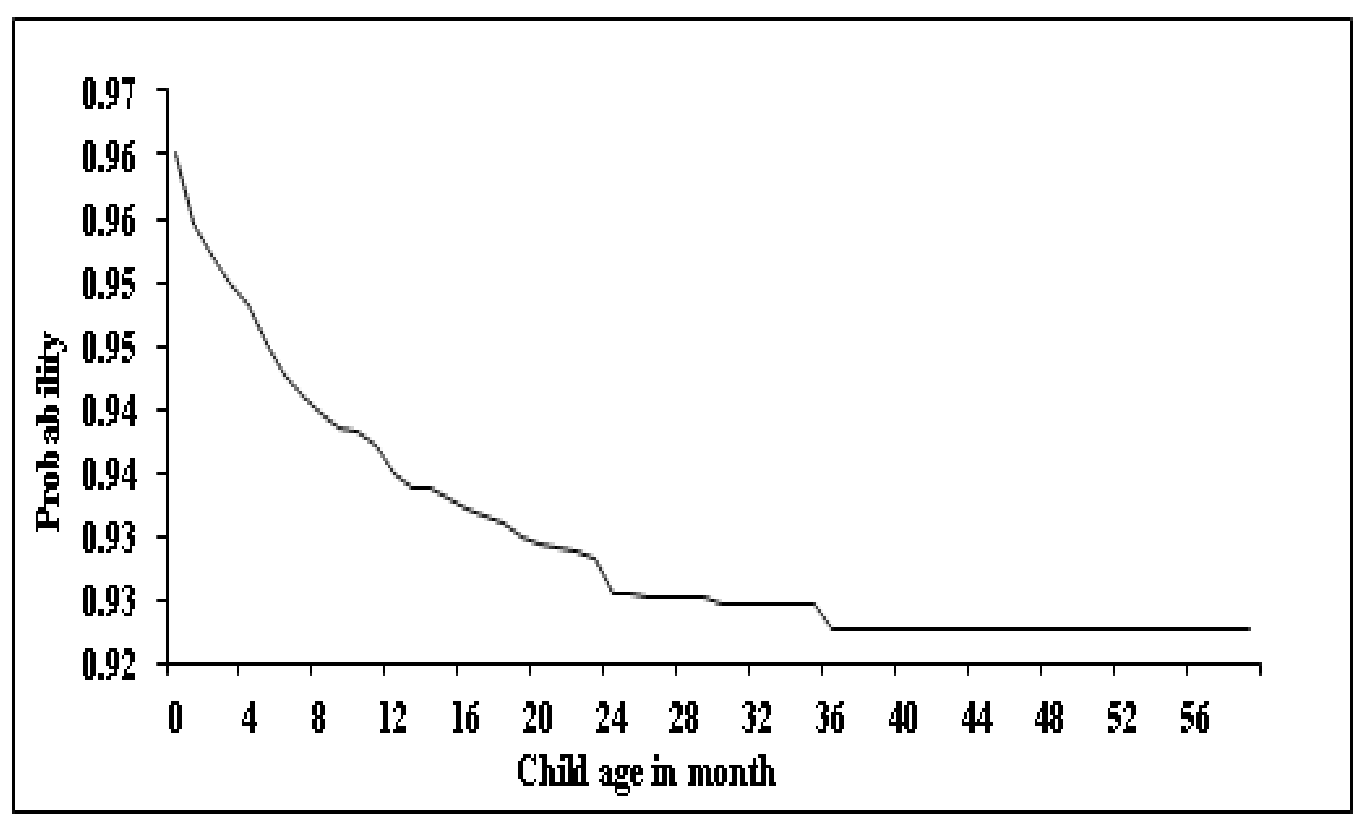

Figure1: Survival function of under-five aged children (0-59 months) for Bangladesh 
Table-3 shows the survival function of under -five aged (0-59 months) children in Bangladesh by Life Table Analysis. The estimation of the duration of child surviving and the estimated proportions still surviving are carried out by using the life table survival analysis approach. Only one detailed life table is shown because for all significant variables these are lengthy and cumbersome. It is seen that probability of child survival starts at 0.9601 and survival probability declines proportionally and at age 35 months is 0.9246 but from age $36-59$ months' children survive at constant rate and which is 0.9228 .

Figure-1 depicts the survival function graph of under-five aged children in Bangladesh. It is seen that child survival starts approximate at $96 \%$ level and it declines proportionally and ends approximately at $92 \%$ level.

\section{Conclusion}

This study examines the predictors of child survival in Bangladesh. It has utilized the national representative data from the Bangladesh Demographic and Health Survey (BDHS) 2014. Both bivariate analysis and life table survival analysis techniques have been applied to identify the significant predictors of child survival in Bangladesh. In spite of the fact that the analysis itself was subject to several sorts of problems including small sample size for survival analysis a numerous interesting decision can be made. Bivariate analysis indicates the association between selected variables and child survival and life table survival analysis determines the survival probability of selected statistically significant variables by bivariate analysis. The findings recommend that parents' education has been identified to be the most important socio-economic predictors of child survival in Bangladesh that means child survival rise with rise in both mother's and father's education level. The study indicates that father's occupation has played significant role in increasing child survival. Socioeconomic status has found to have significant association with child survival by bivariate analysis and it also has found significant effect on child survival by life table analysis. Some characteristics have less effect on child survival; these are region, mother's access to mass media, type of place of residence and type of toilet facility. Several bio-demographic variables have a substantial effect on child survival. Among these variables breastfeeding status, birth order, birth spacing with previous child, age of mother and age of first marriage have been found by both bivariate and life table survival analysis. The antenatal visit during pregnancy has a principal effect on child survival in Bangladesh. Therefore, attention should be given to parents' education and occupation of father, to ensure toilet facility for all and mothers' access to mass media, encourage mother to breastfeed to child, make conscious to mother to give birth at child bearing age 20-34 years, getting married at legal age, birth interval should be more and maternal health care factors in order to increase the child survival in Bangladesh.

\section{ACKNOWLEDGEMETS}

The author is working as an Assistant Professor, Department of Business Administration, International Islamic University Chittagong, Bangladesh and Ph.D Fellow under the Department of Statistics, Anadolu University, Eskisehir, Turkey. He is grateful to these university.

\section{RRFERENCES}

[1] Chowdhury, A.H, Hossain, M.E, Khan, M.M\&Hoq, M.N. (2013). Cox’s Proportional Hazard Model Analysis of Child Survival in Bangladesh. Asian Journal of Social Sciences and Humanities, 2(2), 608618.

[2] Al-Kabir, A. (1984). Effect of Community Factors on Infant and Child Mortality in Rural Bangladesh. London: World Fertility Survey.

[3] Bhuiyan, A. (1989). Factors Affecting Child Survival in Matlab, Bangladesh, PhD Thesis Paper. Department of Demography. Australian National University.

[4] Caldwell, J. C. (1979). Education as a factor in mortality decline: an examination of Nigeria Data. Population Studies, 33(3), 395-413.

[5] Census Commission. (1977). Report on the Bangladesh Retrospective Survey of Fertility and Mortality. Dacca: Census Commission, Ministry of Planning.

[6] Chowdhury, A. K. (1981). Infant Deaths, Determinants and Dilemmas, Scientific Report No. 46. Dacca: ICDDR, B.

[7] Cox, D. R. (1972). Regression Models and Life Tables (with Discussion). Journal of the Royal Statistical Society, Series B (34), 187-220. 
[8] Islam, S. M. \&Alam, M. F. (1996). Factor affecting child mortality in Bangladesh. The Journal of Family Welfare, 42(3), 13-18.

[9] Majumder, A. K. \& Islam, S. M. (1993). Socio-economic and Environmental Determinants of Child Survival in Bangladesh. Journal of Biosocial Science, 25(3), 311-318.

[10] National Institute of Population Research and Training (NIPORT). (2014). Bangladesh Demographic and Health Survey-2014. Dhaka, Bangladesh: Mitra and Associates, Dhaka, Bangladesh, Macro International, Calverton, Maryland USA: Dhaka.

[11] Trussell, J. \& Slough, H. C. (1983). A hazard model analysis of the covariance of infant and child mortality in Sri Lanka. Demography, 20(1), 1-26.

[12] Kabir, A. Kabir, M. and Shahjahan,M. (2012). Life table estimate of child mortality and influence of community factors on child mortality in rural Bangladesh. Jahangirnagar University Journal of Social Sciences (JUJSS)31, 11-24.

Citation: Md., Musa Khan. "Life Table Analysis of Child Survival of Under-Five Age (0-59 Months) Children in Bangladesh." vol 3, no. 3, 2017, pp. 6-15. doi:http://dx.doi.org/10.20431/2454-8677.0303002.

Copyright: (C) 2017 Authors. This is an open-access article distributed under the terms of the Creative Commons Attribution License, which permits unrestricted use, distribution, and reproduction in any medium, provided the original author and source are credited. 